\title{
Analysis of retinal cell development in chick embryo by immunohistochemistry and in ovo electroporation techniques
}

\author{
Sung Tae Doh', Hailing Hao', Stephanie C Loh', Tapan Patel', Haim Y Tawil', David K Chen ${ }^{1}$, Anna Pashkova',
} Andy Shen ${ }^{1}$, Huimin Wang ${ }^{2}$, Li Cai ${ }^{1 *}$

\begin{abstract}
Background: Retinal cell development has been extensively investigated; however, the current knowledge of dynamic morphological and molecular changes is not yet complete.

Results: This study was aimed at revealing the dynamic morphological and molecular changes in retinal cell development during the embryonic stages using a new method of targeted retinal injection, in ovo electroporation, and immunohistochemistry techniques. A plasmid DNA that expresses the green fluorescent protein (GFP) as a marker was delivered into the sub-retinal space to transfect the chick retinal stem/progenitor cells at embryonic day 3 (E3) or E4 with the aid of pulses of electric current. The transfected retinal tissues were analyzed at various stages during chick development from near the start of neurogenesis at E4 to near the end of neurogenesis at E18. The expression of GFP allowed for clear visualization of cell morphologies and retinal laminar locations for the indication of retinal cell identity. Immunohistochemistry using cell type-specific markers (e.g., Visinin, Xap-1, Lim1+2, Pkca, NeuN, Pax6, Brn3a, Vimentin, etc.) allowed further confirmation of retinal cell types. The composition of retinal cell types was then determined over time by counting the number of GFP-expressing cells observed with morphological characteristics specific to the various retinal cell types.

Conclusion: The new method of retinal injection and electroporation at E3 - E4 allows the visualization of all retinal cell types, including the late-born neurons, e.g., bipolar cells at a level of single cells, which has been difficult with a conventional method with injection and electroporation at E1.5. Based on data collected from analyses of cell morphology, laminar locations in the retina, immunohistochemistry, and cell counts of GFPexpressing cells, the time-line and dynamic morphological and molecular changes of retinal cell development were determined. These data provide more complete information on retinal cell development, and they can serve as a reference for the investigations in normal retinal development and diseases.
\end{abstract}

\section{Background}

The vertebrate retina contains seven major cell types, six neuronal and one glial. These cells are derived from multipotent retinal stem/progenitor cells. Previous studies have revealed that the development of the vertebrate retina is a conserved process of cell genesis with the following order of cell birth: ganglion cells, horizontal cells, cone photoreceptors, amacrine cells, bipolar cells, rod photoreceptors, and Müller glia. Similar to

\footnotetext{
* Correspondence: Icai@rutgers.edu
'Department of Biomedical Engineering, Rutgers University, 599 Taylor Road,

* Correspondence: Icai@rutgers.edu
'Department of Biomedical Engineering, Rutgers University, 599 Taylor Road, Piscataway, NJ 08854, USA
}

(c) 2010 Doh et al; licensee BioMed Central Ltd. This is an Open Access article distributed under the terms of the Creative Commons Attribution License (http://creativecommons.org/licenses/by/2.0), which permits unrestricted use, distribution, and reproduction in any medium, provided the original work is properly cited. other parts of the central nervous system, the retina contains a layered structure with photoreceptors (rods and cones) located in the outer nuclear layer $(\mathrm{ONL})$, short projection neurons (bipolar cells) and local circuit neurons (horizontal and amacrine cells) in the inner nuclear layer (INL), and long projection neuron (ganglion cells) in the ganglion cell layer (GCL) [1]. During early stages of retinal development, the outer neuroblastic layer (ONBL) consists almost entirely of mitotic progenitor cells, while newborn neurons (mostly consisting of amacrine and ganglion cells) reside in the inner neuroblastic layer (INBL). The position of mitotic progenitors within the ONBL varies depending upon their 
progress through the cell cycle, with S phase cells found on the vitreal side of the ONBL near the border with the INBL and M-phase cells found on the scleral side of the ONBL abutting the retinal pigment epithelium $[2,3]$.

An important aspect in understanding retinal anatomy and function is to trace the development of various cell types during embryonic stages. Although significant progress has been made, a complete developmental process underlying retinal cell differentiation during embryonic development is still lacking. Previous studies have provided information of retinal development on the rate of progression through the cell cycle [4-7], the mode of cell divisions, e.g., symmetrical versus asymmetrical [8-15], cell migration [16], and the order of cell birth [2,3,17-20]. A cell is born when it withdraws from the cell cycle and undergoes differentiation. These studies are mainly based on DNA synthesis analysis using tritiated-thymidine $\left({ }^{3} \mathrm{H}\right.$-TdR) or 5'-bromon-2'deoxy-uridine (BrdU) labeling methods. ${ }^{3} \mathrm{H}-\mathrm{TdR}$ or BrdU is incorporated into the genomic DNA of stem/progenitor cells during the S-phase of cell cycle before they withdraw from the cell cycle and undergo differentiation. These methods are particularly useful in determining the start and end of cell genesis. In addition, using cell type-specific markers, the onset of differentiation can be determined by identifying the earliest time points for which immunolabeling is observed [21,22]. However, a major drawback to these methods is that DNA replication occurs in the nuclei thus only the nuclei of the labeled cells are observed. In addition, many cell type-specific markers also label only the nuclei of cells. Cell type-specific markers may be able to distinguish between cellular subtypes but fail to reveal the subtle morphological differences that determine key functional differences. Furthermore, morphological changes were observed in previous studies of retinal degenerative diseases caused by mutation or loss of gene function $[23,24]$. Thus, important morphological information of the whole cell that accompanies molecular changes is critical to understanding normal development and disease states.

Here, we report studies aimed at revealing dynamic morphological and molecular changes in retinal cell development of the chick embryo. A plasmid DNA that expresses green fluorescent protein (GFP) as a marker was directly delivered into the embryonic chick subretinal space and electric pulses were applied to facilitate DNA uptake by retinal stem/progenitor cells using a rapid and convenient in ovo electroporation technique. With this technique, GFP-expressing plasmids were efficiently transfected into retinal stem/progenitor cells with little damage to the chick embryos. GFP expression has been found in all cell types of the developing chick retina and allowed for clear visualization of cell morphologies. Immunohistochemistry was performed to further confirm retinal cell types with specific molecular markers. By tracking the cell counts of various cell types based on cellular morphology, laminar location, and molecular markers, the composition of various cell types of the developing retina at different stages has been determined. Thus, this study provides more complete insight into both the morphological and molecular changes during chick embryonic retinal development.

\section{Results}

The chick embryo has been the most advanced model organism suitable for experimental embryology and for studying the development of higher vertebrates [25]. In this report, the chick retina was used for the study of cellular morphological and molecular changes during embryonic development using in ovo electroporation and immunohistochemistry techniques. All results reported in this study were focused on the central portion of the developing chick retina.

\section{Onset and expression pattern of retinal cell type-specific markers}

To determine the onset of the marker expression of various cell types in the embryonic chick retina, cell typespecific antibodies, e.g., Visinin [26] and Xap-1 [27] for photoreceptors; Lim1+2 for horizontal cells [28-32], and Brn3a for ganglion cells [21,33-35] were used to stain retina sections harvested at various time points during retinal development from E4 to E18 (Fig. 1). The development of the many retinal cell types could be tracked independently by observing the onset and dynamic changes in expression patterns of these cell type-specific markers as detected by immunofluorescence labeling.

The expression of a photoreceptor marker Xap-1 [27,36-38] was observed only in the outer segment of the outer nuclear layer (ONL), and its expression starts sometime between E8 and E10 (Fig. 1A-D). The intensity of Xap-1 labeling continued to increase through E18 (Fig. 1E-F). The expression of another photoreceptor marker Visinin, a retinal photoreceptor protein which is believed to be cone specific $[22,26,39]$, starts around E4 (Fig. 1G) which is much earlier than Xap-1 expression. At E6, its expression had increased in intensity but individual cells were still distinguishable (Fig. 1H). Visinin labeling then increased in intensity and the labeled cells composed a significant portion of the ONL at E8 (Fig. 1I). The intensity of Visinin labeling continued to increase and peaked at about E10 (Fig. 1J) when it was expressed in the entire ONL. In later stages (Fig. 1K-L), Visinin labeling continued to remain strong in the outer segment but diminished in the inner segment of the ONL. The differences in expression may suggest that Xap-1 and Visinin coincide with different stages of photoreceptor development. Other photoreceptor specific antibodies against Recoverin and Xap-2 did not show 


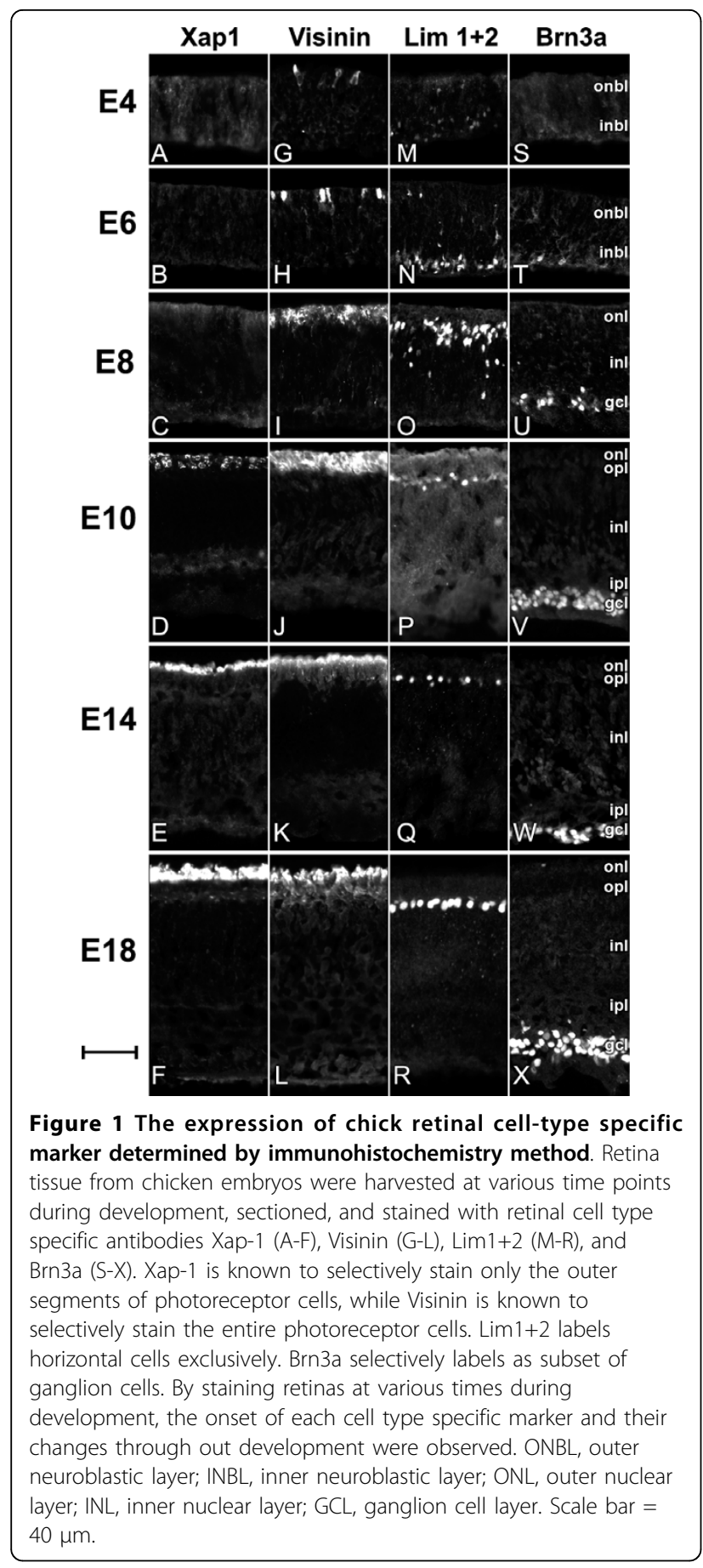

immunoreactivity in any of the stages (E4-E18) of chicken retina tested (results not shown).

The expression of a horizontal cell marker Lim $1+2$ [28-31] started in the retinal neural epithelium around E4 (Fig. 1M). A few Lim1+2 positive cells were observed in the inner neuroblastic layer (INBL) where newborn neurons appear. At E6 (Fig. 1N) the majority of Lim1+2 positive cells are near the edge of INBL, while some are migrating through the inner nuclear layer (INL) towards the outer portion of the INL where mature horizontal cells reside. Migration of Lim $1+2$ positive cells continues through E8 (Fig. 1O) and nears completion by E10 (Fig. 1P) when cells begin to align as a single layer adjacent to the ONL where synaptic endings of the photoreceptor cells located. By E14 (Fig. 1Q), the majority of Lim1 +2 positive cells align on the outer portion of the INL. The space between the Lim $1+2$ positive horizontal cells were almost evenly spaced. This pattern was observed in all the later stages during chick retinal development. The horizontal cells at E18 (Fig. 1R) appear to be more mature than previous stages with larger and more oval cell bodies and are better aligned to the outer most region of the INL.

The expression of a retinal ganglion cell marker Brn3a $[21,34,35]$ was observed to start in the GCL around E6 (Fig. 1T). Brn3a positive cells were organized into 3-4 cell layers in thickness by E8. Brn3a expression increased significantly in both intensity and in number of cells that expressed Brn3a at E8 (Fig. 1U), and its expression was restricted to the GCL. This increasing trend of staining continued at E10 (Fig. 1V) when the majority of cells in the GCL were Brn3a-positive. The borders of the INL, GCL, and the optic nerve fiber layer were clearly defined by Brn3a expression. From E10 (Fig. 1V) to E18 (Fig. 1X), Brn3a expression remained constant. The expression pattern of Brn3a at E21 (data not shown) was similar to that observed from E10 to E18.

In addition, the expression pattern of neuronal specific markers, e.g., Pax6 and NeuN, and a radial glial cell/progenitor cell marker, Vimentin, were also examined (Fig. 2). Vimentin is an intermediate filament protein that is responsible for maintaining cell integrity [40] and is used to label radial glial cell/progenitor cell and Müller glia cells in the chicken retina [41,42]. Müller glia cells span all the retinal layers, possess radially polarized processes, and have arborizations called "end-feet" toward the GCL [41]. Vimentin positive cells were found in all stages tested (Fig. 2A-F) and were not seen to be specific to any cell layer. The Vimentin positive cells showed distinct striated banding throughout all layers. Immunoreactivity was usually most intense in the GCL, which is likely caused by the high concentration of processes in the end-feet of radial/Müller glial cells. Pax6 is a nuclear marker for ganglion, amacrine, and progenitor cells that is required for multipotency in retinal cells [42]. Pax6 was first detected at E4 in a small number of progenitor cells located in the INBL (Fig. 2G). Over the next few days, the overall number of cells detected increased and by E8 (Fig. 2I) included cells located in the INL. At E10 (Fig. 2J), ganglion cells, amacrine cells, and migrating cells are all clearly labeled by Pax6. By 
E16 (Fig. 2l), as found in previous reports, some horizontal cells are also labeled but labeling is weaker than that found in amacrine or ganglion cells [43]. NeuN is a neuron-specific nuclear protein marker [44]. The onset of immunoreactivity of this marker indicates terminal differentiation of the neuron. Previously, use of NeuN antibodies in the mouse retina showed immunoreactivity in the GCL and to a much lesser extent in the INL [44]. In the chicken retina, NeuN labeling is seen in the INBL beginning at E6 (Fig. 2N), and in the INL at E8 (Fig. 2O). By E10 (Fig. 2P), the INL and GCL can be very easily distinguished by the NeuN expression pattern. The intensity of NeuN expression was more intense and widespread in the GCL than the INL at E12 (Fig. 2Q). By E16 (Fig. 2R), the entire GCL and amacrine cell portion of the INL were labeled by NeuN.

\section{Morphological analysis of developing chick retina using} in ovo electroporation technique

To reveal the dynamic morphological changes during retinal cell development, the in vivo electroporation method was adapted and optimized for chick retinal study (in ovo electroporation) [45,46]. Although in ovo electroporation is a widely used technique for the study of neural development, the technique has been mainly performed in neural tube injection and electroporation. Targeted retinal injection and in ovo electroporation at E3-4 is considered a novel method for the study of chick retinal development (See Methods section for technical detail). The pCAG-GFP DNA was injected into the sub-retinal space of E3-E4 chicken embryo (Fig. 3A-D) followed by electroporation (Fig. 3E-F). The plasmid DNA construct, pCAG-GFP, was previously shown to produce ubiquitous GFP expression without altering normal development [45]. In ovo electroporation of pCAG-GFP consistently resulted in the highest level of GFP expression in the central retina with decreasing GFP expression in more peripheral regions of the retina. Few if any cells in the peripheral retina were observed to express GFP (Fig. 3G-H). Immunohistochemistry revealed GFP expression in retinal stem/progenitor cells during early chick embryonic retinal development (Fig. 4A-B), and all six differentiated major cell types during late chick embryonic retinal development (Fig. 4C-F and Fig. 5). Visualization of cytoplasmic GFP expression revealed the cross section morphology of cell bodies and processes (axons and dendrites). The location of individual cells with respect to the retina layers was also clearly visible (Figs. $4 \& 5$ ). The determination of a specific retinal cell type was based on the cellular morphology, laminar location, and expression of molecular markers of the cell.

By observing development between E7 (Fig. 4A) and E18 (Fig. 4F), the changes in laminar location were determined. During early development, the vast majority

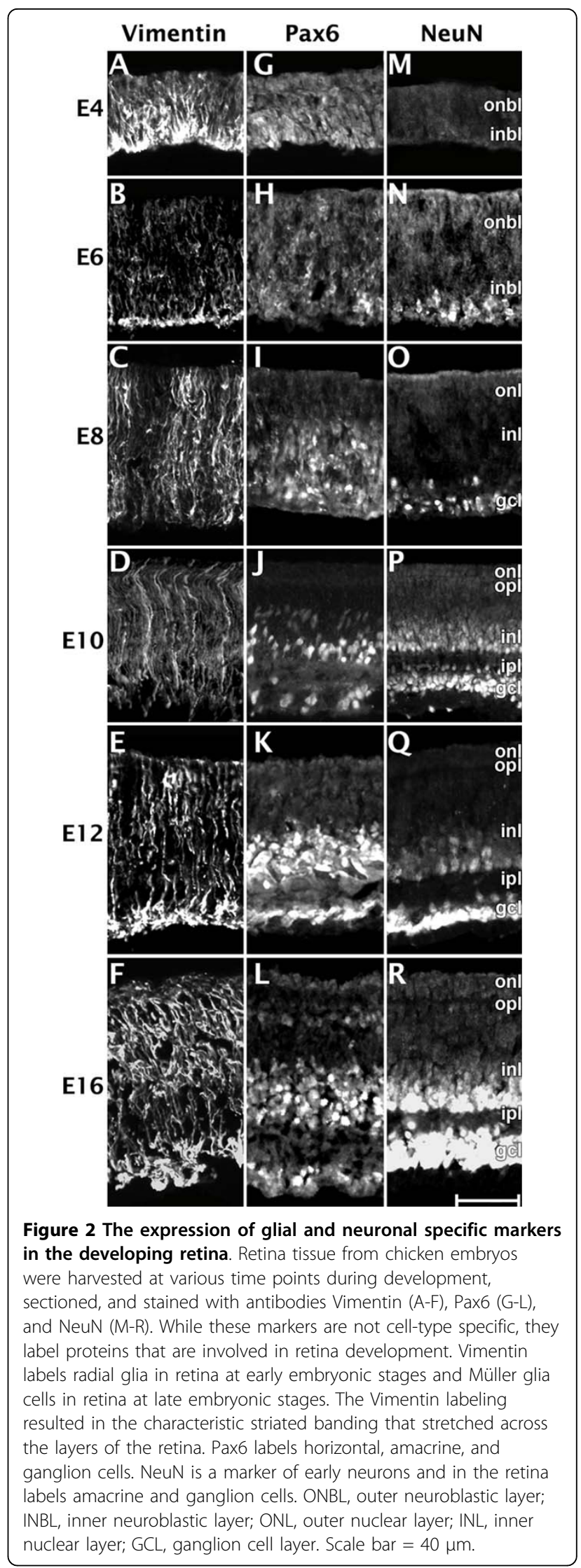




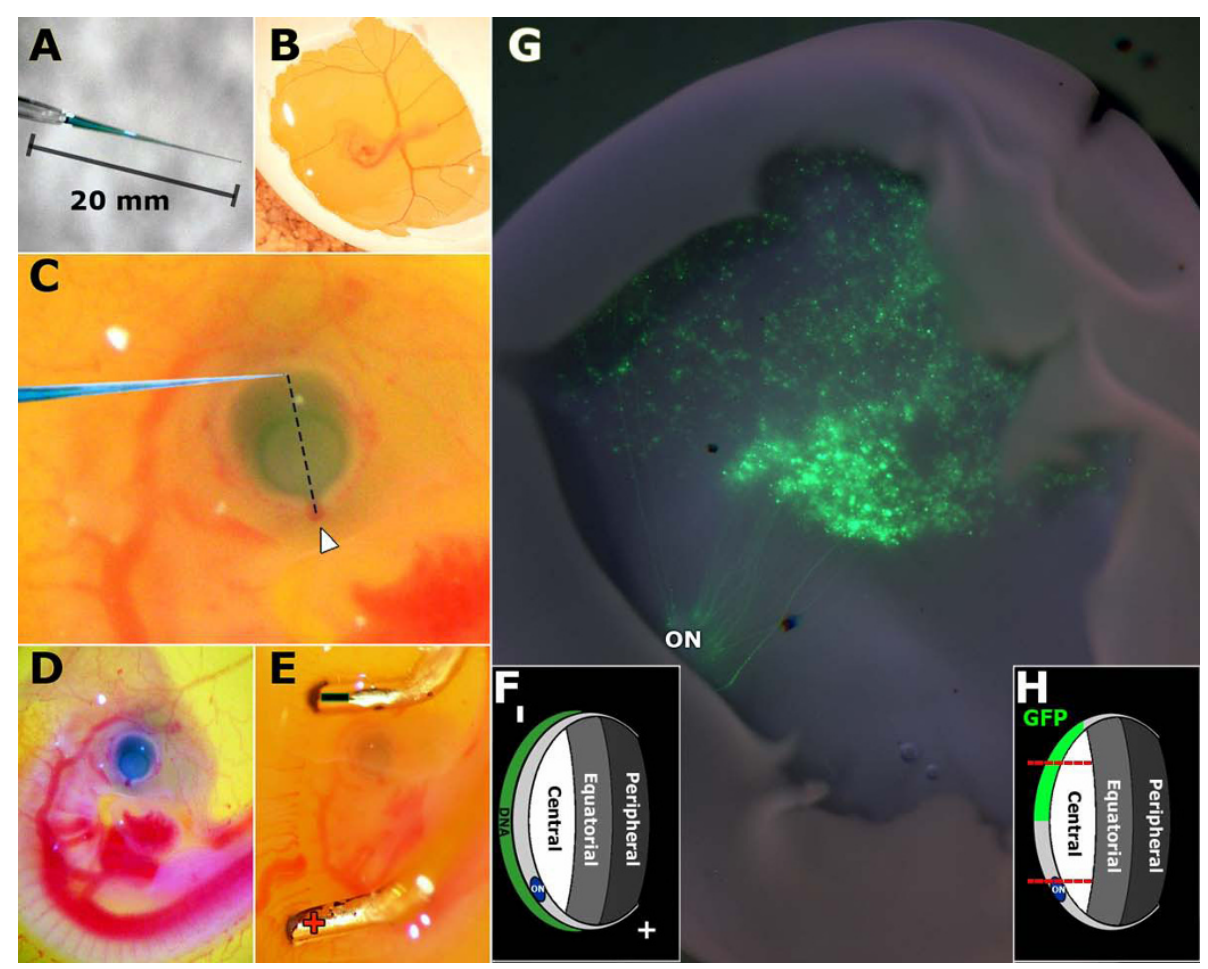

Figure 3 In ovo electroporation method targeting E3-E4 chicken retina. Glass capillary tubes were pulled to fabricate needles with a tip opening at $0.1 \mu \mathrm{m}$ in diameter and a $20 \mathrm{~mm}$ taper (A). The needle is loaded with DNA/0.025\% fast green solution. Eggs were rotated to release the embryo and the shells were sterilized by wiping with $70 \%$ ethanol then windowed using forceps (B). The trajectory of the needle approached the eye from behind the head, toward the beak, and tangent to the retina surface (C). The outermost region of the retina opposite of the main bundle of blood vessels entering the eye (arrowhead, C) was targeted for injection. Successful injection was verified by observing that the subretinal space of the eye was filled with DNA/fast green solution (D). Electroporation was performed with the negative electrode placed above the head of the embryo and deeper in the albumin than the eye. The positive electrode was placed below the spine and on the surface of the albumin (E). Electroporation using this orientation drives the DNA in the subretinal space toward the positive electrode and into the retinal progenitor cells (F). The egg was sealed and incubated until tissue harvest at desired time points. Electroporated retinal tissues were then checked for GFP expression. A wholemount image of a retina with GFP expression at E14 (G) shows axons of ganglion neurons originating in the central retina and extending to the optic nerve $(\mathrm{ON})$. Approximately $1 / 3$ of the central retina was transfected with decreasing levels of GFP expression in more peripheral regions $(G, H)$. Using this method of electroporation at E3-4, the central region of the developing chick retina (area between the two red dotted lines in $\mathrm{H}$ ) was consistently and stably transfected with pCAG-GFP throughout in ovo developmental stages.

of cells are still proliferating and some have started their migration process (Fig. 4A-B). Migratory cells have elongated cell bodies that can span both the ONBL and INBL (arrows in Fig. 4A-B). Once migratory cells reach their respective laminar locations (Fig. 4C-E), they terminally differentiate into specific mature cell types. Differentiated cells (Fig. 4F and Fig. 5) have cell type-specific morphologies and more defined axons and dendrites. At E18, the characteristic morphologies and locations of all six major cell types found in a more developed retina were clearly seen through GFP labeling (Fig. 5). Visualization of GFP allows for the cell bodies as well as the processes (axons and dendrites) to be observed in great detail. Photoreceptor cells (Fig. 5A) are localized exclusively in the ONL and have elongated cell bodies like rods and cones that span the ONL. Their synaptic bodies are found along the boundary of the ONL and the outer plexiform layer (OPL). Horizontal cells (Fig. 5B) have oval cell bodies found in the region of the INL closest to the OPL. Their cell bodies align in a single cell layer with dendrites in the OPL that reach towards the ONL. Ganglion cells (Fig. 5C) are located in the GCL, their cell bodies seem to be the largest in all cell types in the retina. Their dendrites reach towards the INL and the inner plexiform layer (IPL). The size of their cell bodies and the number of dendrites can greatly vary depending on their subtype. Morphologically distinct cells (cell body size, process number, and process direction) were observed in the GCL at E18 (Fig. 4F, Fig. 5C). Based on the laminar location of these observed cells and the known morphological diversity among ganglion cells, it is concluded that multiple subtypes of ganglion cells were able to be labeled by this technique. Müller glial cells (Fig. 5D) are the principal 

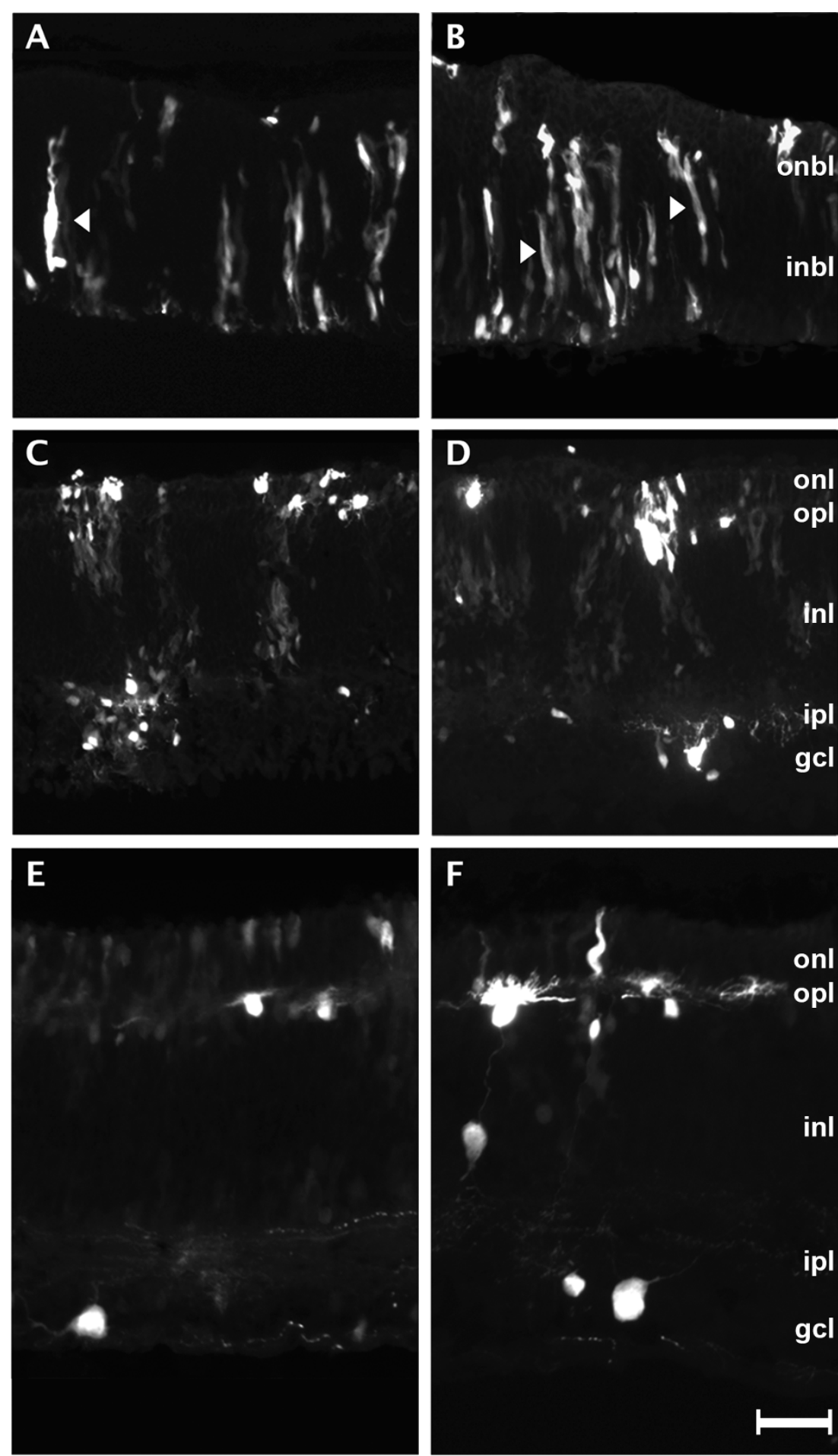

Figure 4 Tracking development and migration of chicken embryonic retina cells using GFP labeling by in ovo electroporation technique. Chicken embryos are injected with pCAG-GFP and electroporated at embryonic day 4 (E4). GFP expression is observed during early stages of development, E7-E8 (A-B). These cells are elongated which is characteristics of cell migration. The cells span the whole width of the neural epithelial layer. In subsequent stages E9-E10 (C-D), cell layers begin to show distinct boundaries and cells begin to settle into their final layers. Cells also take on a rounder morphology and begin to extend their processes. The appearance of well defined cell type specific morphologies begins around E12 (E). Processes are more clearly visible and help to form clearly visible boundaries between layers. The clearest and most distinct and definitive cell morphologies are observed in GFP-expressing cells at E18 (F) (see Fig. 4). ONBL, outer neuroblastic layer; INBL, inner neuroblastic layer; ONL, outer nuclear layer; INL, inner nuclear layer; GCL, ganglion cell layer. Scale bar $=50 \mu \mathrm{m}$. 


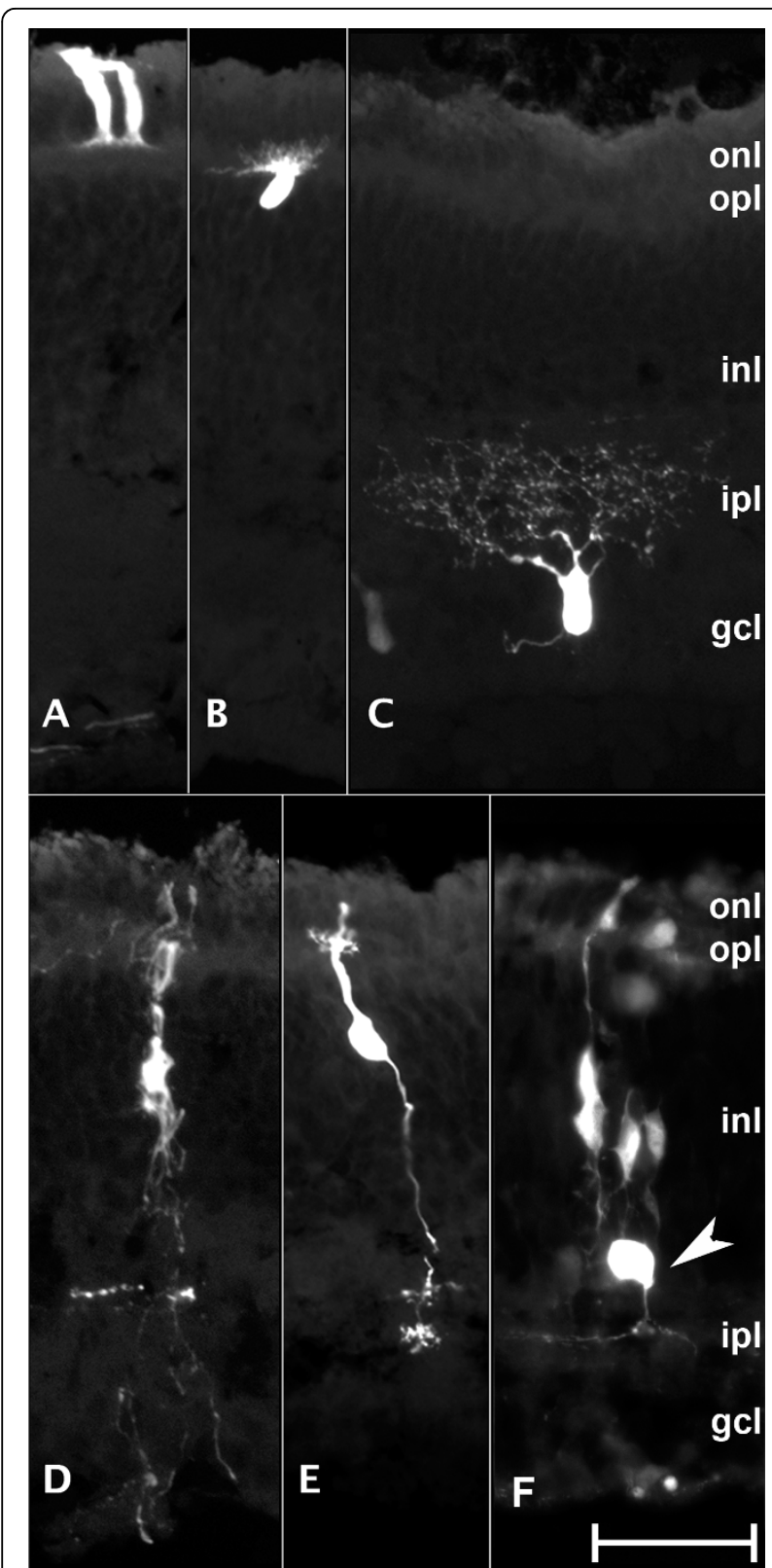

Figure 5 Characteristic morphology of various cell types in chicken retina at E18 with GFP labeling by in ovo electroporation technique. Expression of GFP is observed in all six cell types found in retina tissue through E18. Visualizing GFP expression at this stage shows cells localized in distinct layers and each of the cell type specific morphologies. Photoreceptors (A) have a cylindrical shape and are located in the outer nuclear layer (ONL). Horizontal cells (B) have processes located at the boundary of the inner nuclear layer (INL) and ONL with their cell bodies in the INL. Ganglion cells (C) are located in the GCL and have processes which mostly point toward the INL. Müller glial cells (D) span the entire retina with their cell bodies in the INL. Bipolar cells (E) have two distinct processes one that extends from the cell body in the INL to the ganglion cell layer (GCL) and the other to the ONL. Amacrine cells (F) have cell bodies in the INL and have processes that extent toward the GCL. OPL, outer plexiform layer; IPL, inner plexiform layer; Scale bar $=20 \mu \mathrm{m}$. glial cells of the retina. They form architectural support structures stretching radially across the thickness of the retina and are the limits of the retina at the outer and inner limiting membrane, respectively. They are also the least frequently found cell type in the retina accounting only about $2.7 \%$ of the total cell population in the mature mouse retina $[2,3]$. Their cell bodies sit in the INL and project thick and thin processes irregularly in either direction to the outer limiting membrane and the inner limiting membrane. Bipolar cells (Fig. 5E) have their cell bodies in the INL and reach from the ONL to the ganglion cell layer (GCL) but have only a single axon and dendrite in opposite directions. Amacrine cells (Fig. 5F) have round cell bodies found in the INL and have a single axon that extends to the inner plexiform layer (IPL) where it then branches out to contact the cells in GCL [47].

\section{Confirming retinal cell type of GFP-expressing cells by immunohistochemistry}

To confirm that cell types were correctly identified by cellular morphology and laminar location and to determine composition of cell types of GFP-expressing cells, immunohistochemistry was performed on E10, E14 and E18 retina sections with pCAG-GFP transfection. The cell types were determined using the GFP images (green cells in Fig. 6) and confirmed by overlaying the images with cell type specific antibody labeling (red cells in Fig. 6). At E10, a large number of GFP-expressing cells have immature cell morphology (Fig. 6A, D, G, J, M, P). However, each cell type has a defined laminar location with cell migration close to completion. The laminar location combined with the morphological characteristics (described above and shown in Fig. 5) allowed for the cell types to be quite accurately determined. The identification of each retinal cell type at E14 (Fig. 6B, E, $\mathrm{H}, \mathrm{K}, \mathrm{N}, \mathrm{Q}$ ) became even easier as the vast majority of cells have already completed migration, and their characteristic morphologies, such as axons and dendrites, were more clearly defined. GFP-expressing cells were stained with a cell type specific antibody, e.g., Xap-1 (Fig. 6A-C) or Visinin (Fig. 6D-F) for photoreceptors, Lim1+2 (Fig. 6G-I) for horizontal cells, Pkca (Fig. 6J-L) for bipolar cells, Brn3a (Fig. 6M-O) for ganglion cells, and Vimentin (Fig. 6P-R) for Müller glial cells. For photoreceptor cells, immunolabeling showed that Visinin and Xap-1 staining was only found in ONL where photoreceptor cells reside. The results of antibody labeling with GFP-expressing cells showed that cells in ONL were positive with Visinin and Xap-1 staining. Visinin and Xap-1 labeled all photoreceptors in the ONL beginning at E10. Xap-1 did not label the whole photoreceptor cell but as previously reported only the outer segment [27]. Xap-1 has been shown to be expressed by photoreceptors exclusively under conditions in which 
the outer segment membranes are properly assembled [36]. The fact that Xap-1 expression was observed in the outer most region of the outer nuclear layer (ONL) beginning at E8 and E10 may indicate that this outer most region stained by Xap- 1 is the developing outer segment of the ONL. Our results further indicate that development of the outer segment of the ONL may start as early as E8. Each of the cells labeled with photoreceptor specific markers were correctly identified based on laminar location and cellular morphology (Fig. 6AF). Lim $1+2$ staining was only found in the outer region of the INL. GFP-expressing cells in the outer border of the INL, with round cell bodies, showed Lim1+2 staining at each of the developmental stages. Pkca has been shown to specifically label bipolar cells in the developing retina [48-50]. Pkca labeling showed no staining at E10 (J). Staining at E14 (K) showed labeled cells intermittently in the INL. Staining became more frequent and more intense at E18 (L) in the INL where bipolar cells reside. Double labeling was first observed at E14 and became more frequent at E18. Double labeled cells were only observed in the INL, showed round cell bodies, and characteristic processes were regularly observed at E18. Brn3a staining was exclusively localized in GCL where ganglion cells reside. A few GFP-expressing cells that showed ganglion cell-type specific characteristics were not labeled with Brn3a (Fig. $6 \mathrm{~N}$, marked with an asterisk). However, this finding does not exclude this cell from being a ganglion cell as Brn3a was shown to label the majority of but not all ganglion cells [47]. Labeling with Vimentin showed striated banding throughout all layers for all the various stages. Double labeling with GFP and Vimentin was not observed at E10 but migrating cells expressing GFP seemed to follow Vimentin labeled cells. Double labeling was first seen at E14 (Q) and only in the processes of the cell (Q-R). At all three stages, individual whole cell bodies were resolved by GFP labeling, as opposed to only the outer segment (Fig. 6A-C), entire layers (Fig. 6D-F), or only the nuclei (Fig. 5 and $6 \mathrm{M}-\mathrm{O}$ ) as resolved using antibody labeling. The molecular identification of retinal cell types confirmed that the cell types of chick retina cells between E10 and E18 could be accurately determined based on cellular morphology and laminar location as revealed by GFP expression.

\section{Dynamic changes in the composition of GFP-expressing} cell types during retinal development

To identify dynamic changes in the developing chicken retina, GFP-expressing cells were counted for each cell type from E10 to E18. At least three retinas with GFP expression were generated for each time point. The cell type of the GFP-expressing cells was determined, categorized, and counted. The percentage of each cell type among the entire population of GFP-expressing cells (composition of each retinal cell type) was calculated at each time point (Fig. 7). Cell types were determined based on their morphology, laminar location, and molecular marker. The cell counts showed a dramatic decrease in the number of migratory cells from E10 to E18 (Fig. 7). This finding indicates that the number of migrating cells decreased steadily as fewer migratory cells were being generated and more migratory cells differentiated during this time frame. By E18, the percentage of migratory cells was less than $1 \%$, suggesting that cell migration almost reached completion. The largest increases in differentiated cell types occurred at E12 for photoreceptors, E14 for horizontal cells, and E16 for bipolar cells and amacrine cells. Ganglion cells did not show significant changes during these time periods. Morphologically mature Müller glia cells were first seen around E14 but still remained in very small proportion at E18.

By E18, the composition of retinal cell types is approximately $41.2 \%$ photoreceptor, $29.5 \%$ horizontal, 9.4\% bipolar, 5.4\% amacrine, $12.3 \%$ ganglion, 1.5\% Müller glia, and $0.7 \%$ migratory cells (Fig. 7 ).

\section{Discussion and Conclusion}

The timing of neurogenesis in the chicken retina was previously determined using $\left[{ }^{3} \mathrm{H}\right]$ tymidine autoradiographs by Prada et al. However, due to technical limitations, retinal cell development with dynamic morphological changes in relation to the changes in molecular markers was not fully determined. To address these limitations, we have adopted existing in ovo electroporation capabilities to develop a new method of in ovo electroporation that can specifically target retinal progenitor cells (E3-E4) resulting in the ability to visualize all six major retina cell types at the single cell level. Conventional methods (electroporation at E1.5) have difficulty labeling late-born neurons in the retina such as bipolar cells. This new method adds important capacities to allow possible future studies where the precise cell morphology of retinal neurons is required. It can also be applied to gain/loss of function studies where a gene of interest can be targeted to study normal development and/or disease of the retina. In this study, we have tracked the morphological and molecular development of each of the cell types in the developing chick retina and determined the relative abundance of each cell type within the total population over a developmentally critical time frame, thereby providing new insights into retinal development.

\section{Photoreceptors}

Almost all vertebrate retinas have two morphological types of photoreceptors (rods and cones) that mediate dim-light, color vision and fine-detail detection [51]. Although autoradiographic studies fail to distinguish 

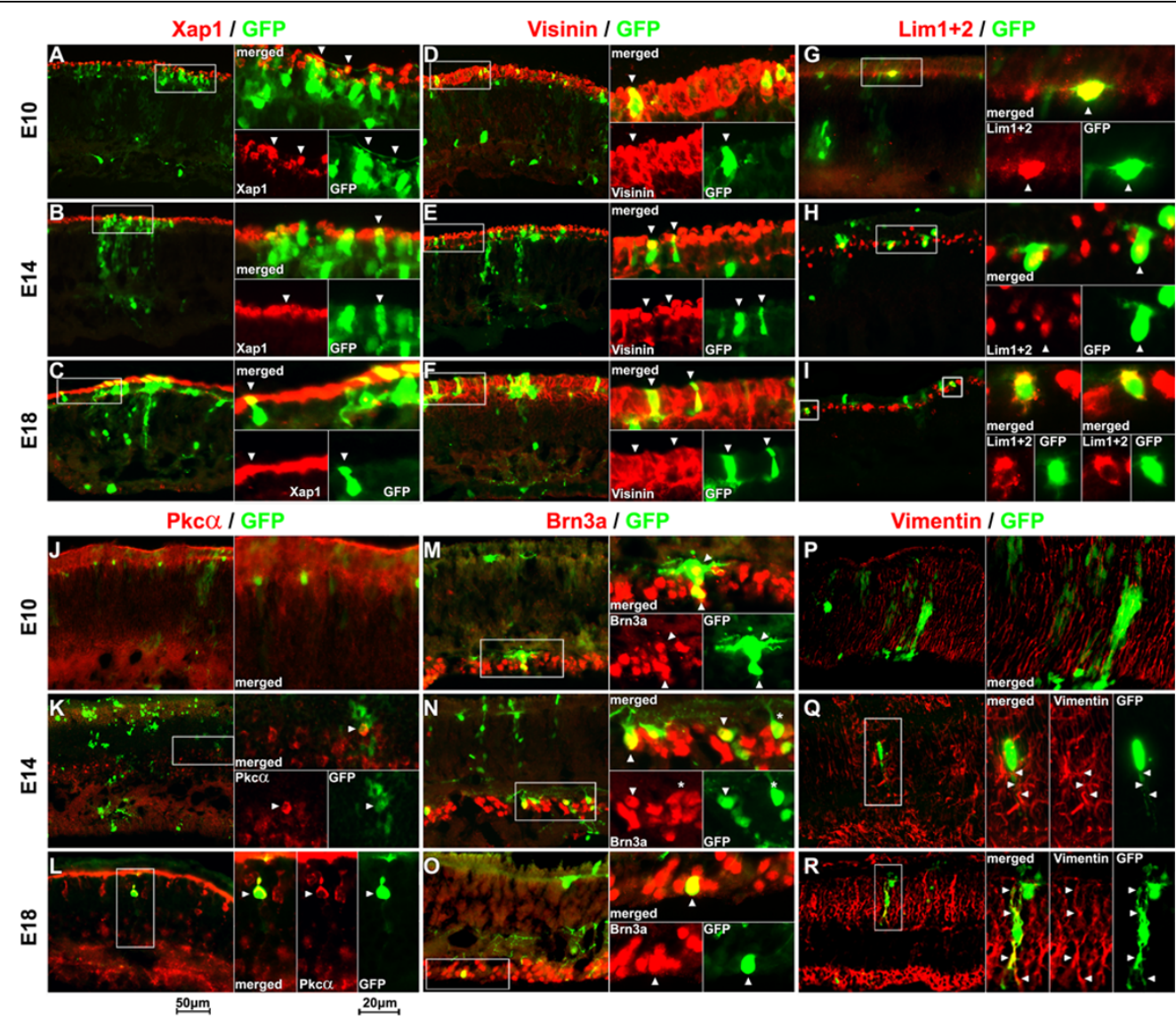

Figure 6 Determine retinal cell type of the GFP-expressing cells using immunohistochemistry method. GFP-expressing retinal tissues at three developmental stages (E10, E14, and E18) were sectioned and stained with retinal cell type specific antibodies, e.g., Xap-1 (A-C) and Visinin (D-F) for photoreceptor cells, Lim1+2 for horizontal cells (G-I), Pkca for bipolar cells (J-L), Brn3a for ganglion cells (M-O), and Vimentin for Müller glial cells (P-R). For each set of images (A-R) the entire retina cross section is shown to allow for the laminar location to be easily visualized. The image on the right shows a merged high magnification image and a pair of separate images showing the antibody staining and GFP fluorescence. The white-boxed region is shown in higher magnification on the right. Double labeled cells are indicated by arrowheads at higher power. Staining with Xap-1 (A-C) and Visinin (D-F) confirmed the identity of GFP-expressing cells in the photoreceptor layer as cone photoreceptors. Lim1+2 labeling consistently labeled cells on the outermost region of the INL. Antibody staining with Pkca failed to label any GFP-expressing cells at E10 (J). The Pkca positive GFP-expressing cells were first seen at E14. Pkco staining increased in both frequency and intensity in GFP-expressing cells at E18. Double labeled cells showed round cell bodies at both E14 and E18 and two distinct processes extending in opposite directions, characteristic of bipolar cells, were regularly observed at E18 (L, GFP). Antibody staining with Brn3a confirms that the GFP-expressing cells (arrowheads in M-O) are ganglion cells. As previously reported Brn3a does not label all ganglion cells. This was seen in E14 tissue (N) where GFP-expressing cells that show ganglion cell morphology and location but no Brn3a labeling (asterisk). Vimentin showed strong labeling at E10 (P) however failed to show double labeling with GFP. Double labeling at E14 (Q) was very rare and slightly more frequent at E18 (R). In both cases double labeling was only seen in the processes of the cells (Q-R, arrowheads).

rods and cones in the chick retina [52,53], ultrastructural studies using scanning electron microscopy confirmed that both rods and cones do exist [54]. However, photoreceptor percentages vary with species, cones being a majority in the chick retina, i.e., $86 \%$ cones versus $14 \%$ rods [55]. In this study, the earliest time we observed photoreceptor marker Visinin expression was at E4 (Fig. 6G-L), which is about two days earlier than it has previously been reported at E6 [22]. Since Visinin preferentially labels cone photoreceptors $[26,39]$, this suggests that cone photoreceptor development in chick begins early at about E4. For rods, antibodies against Rhodopsin and Recoverin were used to immunostain the developing chick retina from E6-E18. No labeling was detected with Rhodopsin and Recoverin antibodies (data not shown), suggesting that either the rod-specific antibodies were not specific to chick rods due to differences in species, or that chick rods differentiate after the examined time-frame (E6-E18).

Horizontal and Amacrine cells

For the study of retinal horizontal cell and amacrine cell development, we used the antibody against Lim $1+2$ 


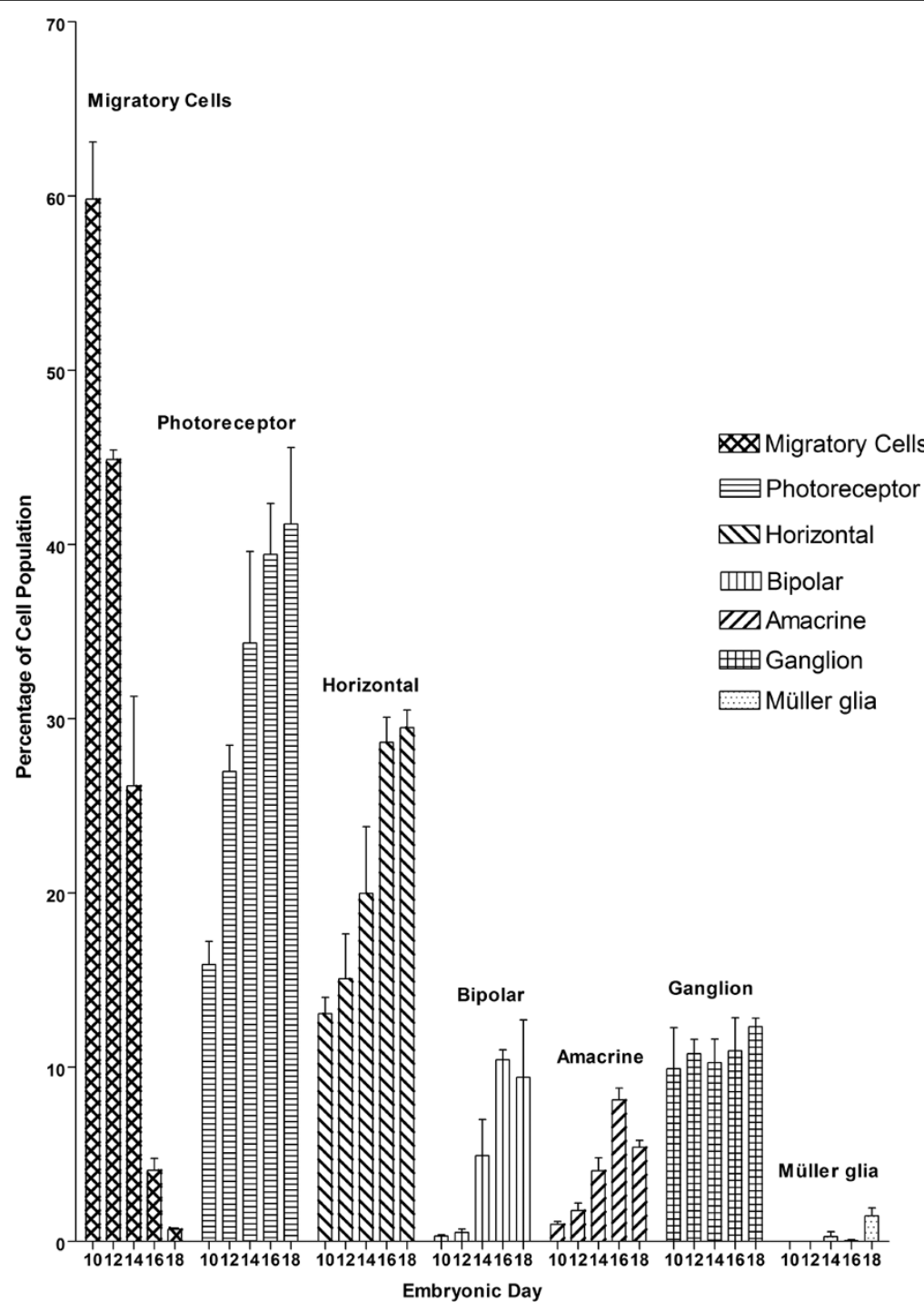

Figure 7 Cellular composition at various stages during embryonic development of the chicken retina. Three retina samples were collected every other day from E10 to E18. Retinal cells expressing GFP were categorized into one of seven cell types based on retinal laminar location, cellular morphology, and molecular marker. Cell counts of each cell type were used to determine the distribution of each cell type during development of the retina. The data shows that the number of ganglion cells remained fairly consistent throughout this time period. Photoreceptors and horizontal cells have a significant increase in population while the increase is less dramatic in bipolar and amacrine cells. As expected, with the increase in other cell types the number of migratory cells decreases.

[28-30,56], Pax6 [43,57] and NeuN [58,59]. Transcription factor Lim1+2 is essential for horizontal cell development and its laminar position in the retina [28,30,60-63]. Pax6 homeobox gene is among the earliest genes expressed in the eye primordia and plays crucial roles in retina development $[32,42,60]$. It is also known to be an amacrine cell marker in later stages (after E8) during embryonic retinal development [43]. By E10, the cells labeled with Pax6 show three distinct layers consisting of migratory cells, amacrine cells, and ganglion cells which can be distinguished using their laminar location. Staining with Lim1+2 antibody showed that horizontal cells began differentiation as early as E4. Lim $1+2$ staining showed that the vast majority of Lim1 +2 expressing horizontal cells completed migration to the outer region of the INL by E10. The dynamic expression pattern of $\operatorname{Lim} 1+2$ during horizontal cell differentiation in our study (Fig. 1M-R) is consistent with previously observations as the differentiating horizontal cells undergo bi-directional interkinetic nuclear migration [30,61]. Pax6 also weakly labeled some horizontal cells after E14. The staining patterns of Lim $1+2$ and Pax6 indicate that amacrine and horizontal cells can be distinguished from each other using laminar location 
information beginning at E10. The DNA-binding, neuron-specific protein $\mathrm{NeuN}$, is present in most neuronal cell types of vertebrates. NeuN stained ganglion cells but labeled very few cells in the INL in adult human retinas [59] and in E12.5 mice [44]. We found that NeuN was strongly expressed in the majority of cells in both the GCL and INL, which is quite different from the one reported in mouse and human. It has been reported that NeuN staining in the adult chick retina is weaker in the INL than in the GCL [64]. This observation suggests that in amacrine cells, NeuN may be most highly expressed shortly after or during differentiation.

\section{Bipolar Cells}

In cell counts of GFP-expressing cells, bipolar cells were not observed with significant frequency until E14. Immunolabeling with $\mathrm{Pkc} \alpha$ antibody was also not observed until E14 supporting the cell count data. Birthdating studies of bipolar cells in rodents showed bipolar cells are among the later born cell types being born postnatally along with Müller cells [2,3]. Consistent with previous studies [53], the bipolar cells in chick retina have been shown to be the last cell type to become postmitotic.

\section{Ganglion Cells}

Previous studies show that ganglion cells are produced over the period from E2 to E9 [53], with all cells initially born in the ventricular zone, followed by immediate differentiation and migration into the future ganglion cell layer [65]. The development of ganglion cells begins at the central region of the developing retina, gradually spreading to the peripheral region as a wave-like front [66]. The composition of GFP-expressing ganglion cells in this report did not show significant changes from E10 to E18, indicating that they were generated before E10. Brn3a is a transcription factor that regulates the development, morphology, and function of retinal ganglion cells $[21,34,35]$. It is expressed specifically in the nuclei of cells that have finished migration and begun differentiating into ganglion cells. Previous findings have shown that Brn3a is expressed as early at E4.5 in the chick retina [33]. Combining the early onset of Brn3a antibody labeling and the consistent percentage of ganglion cells from E10 to E18, it is believed that the vast majority of ganglion cells complete development before E10. This observation is consistent with previous finding that all ganglion cells are born before E9 [53]. Since multiple subtypes of ganglion cells express GFP after in ovo electroporation of pCAG-GFP, the fact that most of the GFP-expressing ganglion cells were also Brn3a-positive (Figs. 1 \&6A-F) indicates that Brn3a labels the majority of ganglion cell subtypes but not all ganglion cells [47]. Müller Glial Cells

The birth dating of Müller glial cells has been controversial. Electron microscopic studies indicate they are born early $[67,68]$. However, results from ${ }^{3} \mathrm{H}-\mathrm{TdR}$ or BrdU labeling indicate that Müller glia cells are labeled only after injections were preformed at late stages during retina development. The immunolabeling results (Fig. 2A-F) show that there is constant expression of Vimentin throughout the embryonic period from E4 to E18. Vimentin is known to label radial glial cells, a type of progenitor cell in the central nervous system [69-71]. Müller glial cells are the only glial cell type in the retina suggesting that Vimentin-positive cells are either mature Müller glial cells in mature retina or retinal stem/progenitor cells in early embryonic retinal development. Radial glial cells or progenitors exist throughout the embryonic stages of retinal development and serve as structurally stabilizing scaffolds [72] and as cell migration guides [73]. GFP-expressing Müller glial cells with mature morphology (Fig. 5D, Fig. 6P-R) could only be observed after E14. The proportion of GFP-expressing Müller glial cells was small, e.g., under $0.3 \%$, at E14 and gradually increased to only $1.5 \%$ at E18 (Fig. 6R and Fig. 7). The low number of morphologically mature Müller glia cells expressing GFP observed between E10 and E18 could be because 1) they are naturally scarce during this time frame or 2) the late birth of Müller glial cells makes them less compatible for labeling using the in ovo electroporation method described. First, the early onset and high frequency of immunoreactivity of Vimentin suggests that a significant number of radial glial/progenitor cells are born as early as E4 and maintain a significant population throughout the examined time frame. Second, if their late birth results in the lack of Müller glial cell labeling, bipolar cells should also be rarely seen, since bipolar cells are born around the same time as Müller glial cells. Third, GFP labeling at E18 showed similar proportions of retina cell population for ganglion cells (which are born early) and bipolar cell (which are born late). Therefore, we believe that the time of birth should not significantly affect the proportion of cell types observed at E18 unless those cells are not yet born. For these reasons, we conclude that the lack of cells with mature Müller glia morphology is not due to their inherent rarity or incompatibility with in ovo electroporation but that the majority of Müller glial cells do not exhibit morphological maturity before E18. A possible explanation for the lack of morphologically mature Müller glia are that they may maintain their progenitor cell (radial glia) state for a significant period of time (at least 14 days) after being born. If this is the case, then the cells that serve as scaffolds and migration guides for the migratory neurons in the retina are radial glia cells/progenitor cells in early embryonic development. In the mouse retina, the majority of Müller glia cells reach morphological maturity late in development $[2,3]$. It is known that many of Müller glial cells 
continue to differentiate postnatally in the chick retina [74]. Alternatively, the staining of Vimentin in microglia cells and proliferating precursor cells is another consideration [75]. Microglia cells are known to be present in small numbers during the development of retina and involved in clearing dying cells that are part of the normal developmental processes $[76,77]$. However, labeling of Vimentin in microglia cells may only slightly contribute to the early onset and high frequency of Vimentin labeling. Furthermore, neither microglia nor proliferating precursor cells can account for the radially polarized staining pattern.

In conclusion, this study reveals the dynamic morphological and molecular changes during a critical period of chick embryonic retinal development. We have demonstrated that in ovo electroporation with pCAG-GFP combined with immunohistochemistry is a very efficient technique for tracing cell proliferation, migration and differentiation processes during retinal development. We were able to identify specific retinal cell types of the GFP-expressing cells based on their morphology and laminar location. The cellular identity of GFP-expressing cells was further confirmed by immunostaining using cell type-specific antibodies. Although, this method has been used in study of retinal development, sustained reporter gene expression in the developing chicken retina has not reported to last for more than a few days $[78,79]$. In ovo electroporation at HH10 ( E2) targeting the optic vesicle is able to transfect cells that develop to form the eye. However, these cells have a very high turnover at this time and this method is not specific for retina cells. It may be that the high cell turnover rate prevents sustained stable expression. By E3, the embryo is developed enough that the major structures of the eye are all formed but young enough that the majority of cells in the retina are still retinal stem cells. The vitelline membrane is thin enough to allow for microinjection and the blood vessels are spaced far enough from the eye to allow for electroporation of the embryo without damaging the vessels. As demonstrated in this study, we were able to optimize the in ovo electroporation method to successfully transfect the retinal stem/progenitor cells at E3-E4 resulting in all 6 major retinal cell types to express GFP through E18. Furthermore, GFP expression clearly shows the cellular morphology that other techniques, e.g., ${ }^{3} \mathrm{H}-\mathrm{TdR}$ or BrdU labeling methods, failed to provide. In rodents, retinas injected and electroporated with pCAG-GFP at postnatal day 0 (P0) did not show GFP expression in early born cells, e.g., horizontal or ganglion cells, which indicates that the generation of these two types are completed by P0 in rodents. By visualizing the morphology of whole individual cells in the developing retina, characterization of each cell type can be performed dynamically during normal development, disease states, or specific over-expression of critical retinal genes. For example, this method can be applied to study the development and growth of the axons and dendrites of particular cell types or applied to produce sustained over-expression or knockdown of developmental genes in the chick retina using alternative DNA constructs. As shown in our results this method can be easily combined with well established immunohistochemistry methods which will be helpful for the understanding of the molecular events that accompany morphological changes during normal development or disease of the retina.

\section{Methods}

\section{Chicken Embryos}

Fertilized pathogen-free (SPF) white leghorn chicken (Gallus domesticus) eggs were obtained from Sunrise Farms (Catskill, NY). These eggs were incubated at $37.5^{\circ}$ $\mathrm{C}$ and $60 \%$ humidity (GQF manufacturing, Savannah, GA) for 88-92 hours ( 3 - 4 days) to obtain embryos that are at the developmental stage HH21. Stages of the chick embryo were determined according to Hamburger and Hamilton [80]. All of the animal experiments were approved by the Institutional Animal Care and Facilities Committee at Rutgers University.

\section{In Ovo Electroporation}

Microinjections were performed using a micropipette needle made from pulled glass capillary tubes with a tip opening at about $0.1 \mu \mathrm{m}$ in diameter and a $20 \mathrm{~mm}$ taper (Fig. 3A). Needles with larger tips have difficulty piercing the vitelline membrane while smaller tips have difficulty loading and delivering the DNA solution. The taper minimizes damage to the embryo while maintaining enough structural integrity in the needle for handling microinjections. The needles were attached to a 0.1 $\mathrm{ml}$ Hamilton Gastight 1710 syringe (Reno, NV) mounted on a WPI M3301-M3 micromanipulator (Sarasota, FL). The needle was loaded with a mixture of DNA (pCAG-GFP; $1.5 \mu \mathrm{l}$ with concentration ranging 3.0-6.0 $\mu \mathrm{g} / \mu \mathrm{l})$ and $0.025 \%$ fast green dye $(0.2 \mu \mathrm{l})$ to allow visualization of the injection (Fig. 3A). This amount of DNA loaded per needle is enough for about a dozen egg injections. The condition and location of the embryo can be seen by candling the egg. The vitelline membrane of the egg was freed from the inner membrane with gentle rotation. The egg was placed with the larger end up and windowed (Fig. 3B) as previously described [46] with minor changes being that the windowing was placed immediately above the air cell and albumen was not removed. The vitelline membrane was not removed as the needle was sharp enough to easily pierce through this membrane. Injection into the vitreous humor allows DNA to diffuse away from the retina and therefore requires more DNA to be 
injected or results in poor transfection. To maximize the travel of the needle point in the subretinal space, the needle should approach the eye such that it is almost at a tangent to the section of the retina targeted for transfection (Fig. 3C). To prevent critical damage to the brain or heart the needle was inserted by approaching from caudal to rostral direction towards the beak. The targeted injection site was along the dorsal region of the eye contralateral to the main bundle of blood vessels entering the eye (Arrowhead in Fig. 3C). When injecting at this angle, continually injecting the DNA while slowly retracting the needle allows visualization of the DNA/ fast green solution either filling the subretinal space or the vitreous humor. Injection of the subretinal space can be verified by the filling of DNA/fast green solution following the outline of the eye (Fig. 3D) rather than diffusing away or filling into the middle of the eye. Every attempt was made to consistently target the same injection site for each embryo to minimize variation from retina to retina. The injection site was electroporated using a BTX ECM 830 electroporation system (Harvard Apparatus, MA). The BTX Genetrodes (model 514) were spaced 3-5 $\mathrm{mm}$ apart. The electrodes were placed in parallel so that the developing eye was situated between the electrodes (Fig. 3E). Electroporation with the electrodes placed in this manner transported DNA located in the subretinal space towards the positive electrode and into the retina (Fig. 3F) resulting in approximately half of the central retina being transfected (Fig. 3G-H). The electroporation settings were 5 pulses of 15 $\mathrm{mV}$ for $50 \mathrm{~ms}$ with $950 \mathrm{~ms}$ pauses between each pulse. After electroporation, the window on the operated eggs was sealed with clear scotch tape, and the egg was returned to the incubator.

\section{Tissue Processing and Sectioning}

Chick embryos were harvested at various times after injection, electroporation, and placed in cold $1 \times$ PBS (Phosphate buffered saline, Fischer Scientific). Retinas were dissected at embryonic day 8 (E8) or older stages, while retinas younger than E8 were left intact in the embryo to minimize damage. Tissues were fixed by immersion in 4\% paraformaldahyde (in $1 \times$ PBS) for 90 minutes at $4{ }^{\circ} \mathrm{C}$ and then infiltrated overnight in $30 \%$ sucrose (in $1 \times$ PBS).

For retinas at E8 and older, the peripheral regions of the cryoprotected retinas were removed to ensure only the central region of the retina was included for analysis. The face of a clock will be used to describe the regions of the whole retina. The retina was oriented such that from an overhead view the dorsal region was oriented at 12 o'clock and the ventral region to the 6 o'clock position. Once situated in this orientation, a first cut is made from the 2 o'clock to the 10 o'clock positions. A second cut is made from the 4 o'clock to the 8 o'clock positions (red dotted lines in Fig. 3H). A third cut from the 1 o'clock to the 5 o'clock positions; and a final cut from the 7 o'clock to the 11 o'clock positions. The resulting square piece in the center is designated as central retina region (see Fig. S1A in additional file 1). In most of the cases, this central square region contained the vast majority of GFP expressing cells.

For retinas younger than E8, the whole eye was sectioned along with the head at the horizontal plane (see Fig. S1B in additional file 1). Only sections of the retina that contain the lens were used to ensure that the central region (CR) of the retina is analyzed. The central region of the retina was defined as the area that opposite to the lens as shown in the fig. S1B in additional file 1.

For embryos injected with pCAG-GFP, successful transfection (Fig. 3G) was verified by examining the retinas under a fluorescent dissection microscope, Leica MZ16FA (Leica Microsystems, Germany) before embedding and sectioning. Tissues were embedded in OCT (Electron Microscopy Sciences, Hatfield, PA) and stored at $-80^{\circ} \mathrm{C}$ until ready for sectioning. Retina tissues sections at $10-15 \mu \mathrm{m}$ were cut using a cryostat (Thermo 0620E), mounted on Superfrost slides (Fisher Scientific) and air-dried. Immunohistochemistry was performed immediately afterwards.

\section{Immunohistochemistry}

For immunofluorescence staining, tissue sections were fixed in 4\% paraformaldahyde for 5 minutes and washed in PBS. Blocking solution (175 $\mu \mathrm{l} ; 0.05 \%$ Triton X-100, $10 \%$ goat serum, $3 \%$ BSA in PBS) was applied on the slide and incubated for 30 minutes at room temperature followed by washing in PBS. Primary antibodies XAP-1 [27] (100 $\mu$ l of 1:10 dilution; DSHB, IA), Xap-2 [27] (100 $\mu$ l of 1:100 dilution; DSHB, IA), Visinin [26] (100 $\mu \mathrm{l}$ of 1:10 dilution; DSHB, IA), rho-4D2 [81] (100 $\mu \mathrm{l}$ of 1:100 dilution; R.S. Molday, University of British Columbia), Lim1+2 (4F2) $[56,82,83](100 \mu \mathrm{l}$ of $1: 10$ dilution; DSHB, IA), Vimentin (H5) [71] (100 $\mu$ l of 1:10 dilution; DSHB, IA), Pax6 [57] (100 $\mu$ l of 1:100 dilution; DSHB, IA), Pkca (100 $\mu \mathrm{l}$ of 1:400 dilution; Santa Cruz Biotechnology Inc, CA), Recoverin [84] (100 $\mu \mathrm{l}$ of 1:100 dilution; Millipore, MA), Brn3a [21] (100 $\mu$ l of 1:100 dilution; Millipore, MA), or NeuN [44] (100 $\mu$ l of 1:1000 dilution; Millipore, MA) were applied to the wet slides. Incubation was carried out in a humidified box on a slow rocker at $4{ }^{\circ} \mathrm{C}$ overnight. As a negative control, serum and secondary antibodies were applied but no primary antibody was added to the staining solution (Fig. S2 in additional file 1). Slides were then washed with PBST (0.1\% Tween-20 in $1 \times$ PBS) and Cy3-conjugated secondary antibodies $(150 \mu \mathrm{l}$ of 1:300 dilution; Jackson ImmunoResearch, West Grove, PA) was applied. After 30 min incubation at room temperature with 
gentle rocking, the slides were washed with PBST then cover slipped. All washes were $5 \mathrm{~min}$ and repeated 3 times unless specified otherwise.

\section{Imaging}

Microscopy and imaging analysis were performed using an upright fluorescence microscope (Zeiss Axio Imager A1) with a monochrome digital camera Axiocam MRM (Zeiss, Germany). Images of GFP-expressing cells and secondary antibody Cy3 labeled cells were taken separately using FITC and DsRed filters, respectively. Imaging of Vimentin-labeled retinas was performed using a confocal microscope (Nikon Eclipse 80i) with a monochrome digital camera Nikon D-Eclipse C1 (Nikon, Japan). Images of GFP-expressing cells and secondary antibody Cy3 labeled cells were taken separately using $488 \mathrm{~nm}$ and $543 \mathrm{~nm}$ wavelengths, respectively. Images of Cy3 and GFP channels were then overlaid using Adobe Photoshop CS to create pseudo-colored doublelabeled images.

\section{Cell counts}

Retinas electroporated with pCAG-GFP were harvested as described above at each time point (E10, E12, E14, E16, and E18). At least three retinas from each time point with confirmed GFP expression were then sectioned and imaged. To avoid counting cells that span multiple sections more than once, only one image was counted from any given set of 5 serial sections.

\section{Determining cell type for cell counts}

In the majority of cases, the morphology and laminar location criteria are sufficient for the determination of a cell type. For photoreceptor cells, Visinin labeling starts in the ONBL as early as E4 and is restricted in the ONL from E8 and beyond. Furthermore no other cell types other than Müller cells were observed through antibody staining to be in the ONL. However, the cell body of Müller cells is generally not located in the ONL. Therefore, all cells restricted to only the ONL were identified as photoreceptors. Horizontal cells, in the time frame of E10-E18, were shown to be strictly restricted to the outermost region of the INL by $\operatorname{Lim} 1+2$ staining. The morphologies as revealed by GFP show round cell bodies with the majority of processes extending toward the OPL. Therefore cells with round cell bodies found in the outermost region of the INL that have processes generally restricted to the OPL were identified as horizontal cells. Ganglion cells were labeled with Brn3a and found only in the GCL between E10 and E18. The cell bodies of ganglion cells are also known to be round and among the largest of all the cell types in the retina. Therefore, cells located in the GCL with round cell bodies were identified as ganglion cells. There may be a small number of displaced amacrine cells that were counted as ganglion cells; however, we believe that this should not significantly affect the accuracy of our cell counts. Bipolar cells were known to be restricted to the INL (which was confirmed by staining with $P k c \alpha$ ) with round cell bodies and two distinct bi-directional processes. The greatest difficulty in identifying this cell type was in distinguishing bipolar cells from Müller cells and migratory cells as each of these cell types could have their cell bodies in the INL. We have found, however, that even in their progenitor state after E10 they do have subtle but distinct morphological characteristics that allow for them to be distinguished from each other. Müller glial cells have multiple branching processes extending from the cell body. Migratory cells have elongated cell bodies and are usually clustered with other migratory cells. Bipolar cells have rounder cell bodies and at most 2 processes which, if present, are transversely opposed from each other. Pax6 is known to label horizontal, amacrine, and ganglion cells. NeuN is known to label amacrine and ganglion cells. Comparing the staining patterns of these two markers between E10 and E18 shows that the inner half of the INL and the GCL are consistently labeled by both markers. Based on these staining patterns amacrine cells were determined to be restricted to the inner half of the INL between E10 and E18. Amacrine cells also have round cell bodies with processes that are directed toward the IPL. Therefore, all cells with round cell bodies, processes directed toward the IPL, and located in the inner half of the INL were counted as amacrine cells. In all cases characteristic laminar location of cell types narrows down the potential identity of the cell, while morphological characteristics which became increasingly distinguished over time increased the accuracy of cell type identification.

\section{Statistical Analysis}

For each cell type, its percentage of the total GFPexpressing cells was calculated each retina. The data was then plotted and the standard error of the mean (SEM) was calculated for each set of retinas of the same time point using Prism version 4.03 (GraphPad Software, Inc. La Jolla, CA).

\footnotetext{
Additional file 1: Fig. S1. Diagram depicting the central region of the retina included for analysis. A. For retinas at E8 and older, the peripheral regions of the cryoprotected retinas were removed to ensure only the central region of the retina was included for analysis. The face of a clock will be used to describe the regions of the whole retina. The retina was oriented such that from an overhead view the dorsal region was oriented at 12 o'clock and the ventral region to the 6 o'clock position. Once situated in this orientation, a first cut is made from the 2 o'clock to the 10 o'clock positions. A second cut is made from the 4 o'clock to the 8 o'clock positions (red dotted lines in Fig. $3 \mathrm{H}$ ). A third cut from the 1 o'clock to the 5 o'clock positions; and a final cut from the 7 o'clock to the 11 o'clock positions. The resulting square piece in the center is designated as central retina region. B. For retinas younger than E8, the whole eye was sectioned along with the head at the horizontal plane. The central region (CR) of the retina was defined as the area that opposite to the lens. Fig. S2. Negative control for antibody staining. Retina tissue from chicken embryos were harvested at E4, E6, and E8, sectioned, and stained with only serum and secondary antibody. ONBL,
} 
outer neuroblastic layer; INBL, inner neuroblastic layer; ONL, outer nuclear layer; INL, inner nuclear layer; GCL, ganglion cell layer. Scale bar $=40 \mu \mathrm{m}$. Click here for file

[http://www.biomedcentral.com/content/supplementary/1471-213X-10-8S1.PDF ]

\section{Acknowledgements}

We would like to thank Dr. Connie Cepko for a reporter construct of plasmid DNA pCAG-GFP, Dr. Robert S. Molday for Rho-4D2 antibody, Dr. Richard Nowakowski for the use of a confocal microscope (Nikon Eclipse 80i), and Evangeline Tzatzalos and Shannon M. Smith for proof-reading the manuscript. Antibodies: Lim1+2 (4F2), Pax6, Vimentin (H5), Visinin (7G4), Xap1 (clone 3D2) and Xap-2 (clone 5B9), were obtained from the Developmental Studies Hybridoma Bank developed under the auspices of the NICHD and maintained by The University of lowa, Department of Biological Sciences, lowa City, IA 52242. This work was supported in part by the grant EY018738 from the National Institute of Health; the New Jersey Commission on Spinal Cord Research grant (08-3074-SCR-E-0); and the Charles and Johanna Busch Award.

\section{Author details}

'Department of Biomedical Engineering, Rutgers University, 599 Taylor Road, Piscataway, NJ 08854, USA. ${ }^{2}$ Institute of Cognitive Neuroscience, East Normal University, Shanghai, PR China.

\section{Authors' contributions}

SD participated in the design of the study, carried out the experiments, and drafted the manuscript. $\mathrm{HH}, \mathrm{SCL}, \mathrm{TP}, \mathrm{HYT}, \mathrm{DC}, \mathrm{AP}$, and AS helped immunohistochemistry and microscopy. AS, DKC, AP, and HW helped the cell counting. LC designed, coordinated, and carried out the experiments, and helped to write and revise the manuscript. All authors read and approved the final manuscript.

Received: 2 June 2009

Accepted: 20 January 2010 Published: 20 January 2010

\section{References}

1. Kaneko A: Physiology of the retina. Annu Rev Neurosci 1979, 2:169-91.

2. Young RW: Cell differentiation in the retina of the mouse. Anat Rec 1985, 212:199-205

3. Young RW: Cell proliferation during postnatal development of the retina in the mouse. Brain Res 1985, 353:229-39.

4. Alexiades MR, Cepko C: Quantitative analysis of proliferation and cell cycle length during development of the rat retina. Dev Dyn 1996, 205:293-307.

5. Gloor BP, Rokos L, Kaldarar-Pedotti S: Cell cycle time and life-span of cells in the mouse eye. Measurements during the postfetal period using repeated 3H-thymidine injections. Dev Ophthalmol 1985, 12:70-129.

6. Fujita S: Kinetics of cellular proliferation. Exp Cell Res 1962, 28:52-60.

7. Li Z, Hu M, Ochocinska MJ, Joseph NM, Easter SS Jr: Modulation of cell proliferation in the embryonic retina of zebrafish (Danio rerio). Dev Dyn 2000, 219:391-401.

8. Rapaport DH, Stone J: The topography of cytogenesis in the developing retina of the cat. J Neurosci 1983, 3:1824-34.

9. Silva $\mathrm{AO}$, Ercole CE, McLoon SC: Plane of cell cleavage and numb distribution during cell division relative to cell differentiation in the developing retina. J Neurosci 2002, 22:7518-25.

10. Das $T$, Payer $B$, Cayouette $M$, Harris WA: In vivo time-lapse imaging of cell divisions during neurogenesis in the developing zebrafish retina. Neuron 2003, 37:597-609.

11. Cayouette M, Raff M: The orientation of cell division influences cell-fate choice in the developing mammalian retina. Development 2003 130:2329-39.

12. Tibber MS, Kralj-Hans I, Savage J, Mobbs PG, Jeffery G: The orientation and dynamics of cell division within the plane of the developing vertebrate retina. Eur J Neurosci 2004, 19:497-504.
13. Tibber MS, Whitmore AV, Jeffery G: Cell division and cleavage orientation in the developing retina are regulated by L-DOPA. J Comp Neurol 2006, 496:369-81.

14. Zigman M, Cayouette M, Charalambous C, Schleiffer A, Hoeller O, Dunican D, McCudden CR, Firnberg N, Barres BA, Siderovski DP, et al: Mammalian inscuteable regulates spindle orientation and cell fate in the developing retina. Neuron 2005, 48:539-45.

15. Godinho L, Williams PR, Claassen Y, Provost E, Leach SD, Kamermans M, Wong RO: Nonapical symmetric divisions underlie horizontal cell layer formation in the developing retina in vivo. Neuron 2007, 56:597-603.

16. Zimmerman RP, Polley EH, Fortney RL: Cell birthdays and rate of differentiation of ganglion and horizontal cells of the developing cat's retina. J Comp Neurol 1988, 274:77-90.

17. Morrow EM, Chen CM, Cepko CL: Temporal order of bipolar cell genesis in the neural retina. Neural Develop 2008, 3:2

18. Gamm DM, Nelson AD, Svendsen $C N$ : Human retinal progenitor cells grown as neurospheres demonstrate time-dependent changes in neuronal and glial cell fate potential. Ann N Y Acad Sci 2005, 1049:107-17.

19. Blanks JC, Spee C, Barron E, Rich KA, Schmidt S: Lineage study of degenerating photoreceptor cells in the rd mouse retina. Curr Eye Res 1997, 16:733-7.

20. Reese BE, Thompson WF, Peduzzi JD: Birthdates of neurons in the retinal ganglion cell layer of the ferret. J Comp Neurol 1994, 341:464-75.

21. Liu W, Khare SL, Liang X, Peters MA, Liu X, Cepko CL, Xiang M: All Brn3 genes can promote retinal ganglion cell differentiation in the chick. Development 2000, 127:3237-47.

22. Bruhn SL, Cepko CL: Development of the pattern of photoreceptors in the chick retina. J Neurosci 1996, 16:1430-9.

23. Morrow EM, Furukawa T, Cepko CL: Vertebrate photoreceptor cell development and disease. Trends Cell Biol 1998, 8:353-8.

24. Furukawa T, Morrow EM, Li T, Davis FC, Cepko CL: Retinopathy and attenuated circadian entrainment in Crx-deficient mice. Nat Genet 1999 23:466-70

25. Stern CD: The chick; a great model system becomes even greater. Dev Cell 2005, 8:9-17

26. Yamagata K, Goto K, Kuo CH, Kondo H, Miki N: Visinin: a novel calcium binding protein expressed in retinal cone cells. Neuron 1990, 4:469-76.

27. Harris WA, Messersmith SL: Two cellular inductions involved in photoreceptor determination in the Xenopus retina. Neuron 1992 9:357-72.

28. Suga A, Taira M, Nakagawa S: LIM family transcription factors regulate the subtype-specific morphogenesis of retinal horizontal cells at postmigratory stages. Dev Biol 2009, 330:318-28.

29. Margeta MA: Transcription factor Lim1 specifies horizontal cell laminar position in the retina. J Neurosci 2008, 28:3835-6.

30. Poche RA, Kwan KM, Raven MA, Furuta Y, Reese BE, Behringer RR: Lim1 is essential for the correct laminar positioning of retinal horizontal cells. $J$ Neurosci 2007, 27:14099-107.

31. Boije $H$, Edqvist PH, Hallbook F: Temporal and spatial expression of transcription factors FoxN4, Ptf1a, Prox1, Is/1 and Lim1 mRNA in the developing chick retina. Gene Expr Patterns 2008, 8:117-23.

32. Edqvist PH, Myers SM, Hallbook F: Early identification of retinal subtypes in the developing, pre-laminated chick retina using the transcription factors Prox1, Lim1, Ap2alpha, Pax6, Is|1, Is|2, Lim3 and Chx10. Eur J Histochem 2006, 50:147-54.

33. Huang EJ, Liu W, Fritzsch B, Bianchi LM, Reichardt LF, Xiang M: Brn3a is a transcriptional regulator of soma size, target field innervation and axon pathfinding of inner ear sensory neurons. Development 2001, 128:2421-32.

34. Nadal-Nicolas FM, Jimenez-Lopez M, Sobrado-Calvo P, Nieto-Lopez L, Canovas-Martinez I, Salinas-Navarro M, Vidal-Sanz M, Agudo M: Brn3a as a marker of retinal ganglion cells: qualitative and quantitative time course studies in naive and optic nerve-injured retinas. Invest Ophthalmol Vis Sci 2009, 50:3860-8.

35. Badea TC, Cahill H, Ecker J, Hattar S, Nathans J: Distinct roles of transcription factors brn3a and brn3b in controlling the development, morphology, and function of retinal ganglion cells. Neuron 2009, 61:852-64.

36. Wohabrebbi A, Umstot ES, lannaccone A, Desiderio DM, Jablonski MM Downregulation of a unique photoreceptor protein correlates with improper outer segment assembly. J Neurosci Res 2002, 67:298-308. 
37. Wikler KC, Rakic P: An array of early differentiating cones precedes the emergence of the photoreceptor mosaic in the fetal monkey retina. Proc Natl Acad Sci USA 1994, 91:6534-8.

38. Rapaport DH, Patheal SL, Harris WA: Cellular competence plays a role in photoreceptor differentiation in the developing Xenopus retina. J Neurobiol 2001, 49:129-41.

39. Hatakenaka S, Kiyama H, Tohyama M, Miki N: Immunohistochemical localization of chick retinal 24 kdalton protein (visinin) in various vertebrate retinae. Brain Res 1985, 331:209-15.

40. Docherty RJ, Edwards JG, Garrod DR, Mattey DL: Chick embryonic pigmented retina is one of the group of epithelioid tissues that lack cytokeratins and desmosomes and have intermediate filaments composed of vimentin. J Cell Sci 1984, 71:61-74.

41. Moscona AA, Fox L, Smith J, Degenstein L: Antiserum to lens antigens immunostains Muller glia cells in the neural retina. Proc Natl Acad Sci USA 1985, 82:5570-3.

42. Marquardt T, Ashery-Padan R, Andrejewski N, Scardigli R, Guillemot F, Gruss P: Pax6 is required for the multipotent state of retinal progenitor cells. Cell 2001, 105:43-55.

43. Belecky-Adams T, Tomarev S, Li HS, Ploder L, Mclnnes RR, Sundin O, Adler R: Pax-6, Prox 1, and Chx10 homeobox gene expression correlates with phenotypic fate of retinal precursor cells. Invest Ophthalmol Vis Sci 1997, 38:1293-303.

44. Mullen RJ, Buck CR, Smith AM: NeuN, a neuronal specific nuclear protein in vertebrates. Development 1992, 116:201-11.

45. Matsuda T, Cepko CL: Electroporation and RNA interference in the rodent retina in vivo and in vitro. Proceedings of the National Academy of Sciences of the United States of America 2004, 101:16-22.

46. Nakamura $H$, Funahashi J: Introduction of DNA into chick embryos by in ovo electroporation. Methods (Duluth) 2001, 24:43-8.

47. Xiang M, Zhou H, Nathans J: Molecular biology of retinal ganglion cells. Proc Natl Acad Sci USA 1996, 93:596-601.

48. Caminos E, Velasco A, Jarrin M, Lillo C, Jimeno D, Aijon J, Lara JM: A comparative study of protein kinase C-like immunoreactive cells in the retina. Brain Behav Evol 2000, 56:330-9.

49. Haverkamp S, Haeseleer F, Hendrickson A: A comparison of immunocytochemical markers to identify bipolar cell types in human and monkey retina. Vis Neurosci 2003, 20:589-600.

50. Shin T, Kim S, Ahn M, Kim H: An immunohistochemical study of protein kinase $C$ in the bovine retina. J Vet Med Sci 2006, 68:71-4.

51. Dowling JE: The retina. An approachable part of the brain Cambridge, MA., USA: Belknap 1987.

52. Kahn AJ: An autoradiographic analysis of the time of appearance of neurons in the developing chick neural retina. Dev Biol 1974, 38:30-40.

53. Prada C, Puga J, Perez-Mendez L, Lopez R, Ramirez G: Spatial and Temporal Patterns of Neurogenesis in the Chick Retina. Eur J Neurosci 1991, 3:1187.

54. Wai MS, Lorke DE, Kung LS, Yew DT: Morphogenesis of the different types of photoreceptors of the chicken (Gallus domesticus) retina and the effect of amblyopia in neonatal chicken. Microsc Res Tech 2006, 69:99-107.

55. Morris VB: Symmetry in a receptor mosaic demonstrated in the chick from the frequencies, spacing and arrangement of the types of retinal receptor. J Comp Neurol 1970, 140:359-98.

56. Tsuchida T, Ensini M, Morton SB, Baldassare M, Edlund T, Jessell TM, Pfaff SL: Topographic organization of embryonic motor neurons defined by expression of LIM homeobox genes. Cell 1994, 79:957-70.

57. Ericson J, Rashbass P, Schedl A, Brenner-Morton S, Kawakami A, van Heyningen $V$, Jessell TM, Briscoe J: Pax6 controls progenitor cell identity and neuronal fate in response to graded Shh signaling. Cell 1997, 90:169-80.

58. Sarnat HB, Nochlin D, Born DE: Neuronal nuclear antigen (NeuN): a marker of neuronal maturation in early human fetal nervous system. Brain Dev 1998, 20:88-94

59. Wolf HK, Buslei R, Schmidt-Kastner R, Schmidt-Kastner PK, Pietsch T, Wiestler OD, Blumcke I: NeuN: a useful neuronal marker for diagnostic histopathology. J Histochem Cytochem 1996, 44:1167-71.

60. Fischer AJ, Stanke JJ, Aloisio G, Hoy H, Stell WK: Heterogeneity of horizontal cells in the chicken retina. J Comp Neurol 2007, 500:1154-71.

61. Edqvist PH, Hallbook F: Newborn horizontal cells migrate bi-directionally across the neuroepithelium during retinal development. Development 2004, 131:1343-51.
62. Poche RA, Reese BE: Retinal horizontal cells: challenging paradigms of neural development and cancer biology. Development 2009, 136:2141-51.

63. Boije H, Edqvist PH, Hallbook F: Horizontal cell progenitors arrest in G2-ph ase and undergo terminal mitosis on the vitreal side of the chick retina. Dev Biol 2009, 330:105-13.

64. SS LJ Cho, AG Hyndman: Transferrin binding protein is expressed by oligodendrocytes in the avian retina. Brain Res 1999, 816:229-233.

65. Waid DK, McLoon SC: Immediate differentiation of ganglion cells following mitosis in the developing retina. Neuron 1995, 14:117-24.

66. Furukawa T, Mukherjee S, Bao ZZ, Morrow EM, Cepko CL: rax, Hes1, and notch1 promote the formation of Muller glia by postnatal retinal progenitor cells. Neuron 2000, 26:383-94.

67. Meller K, Tetzlaff W: Scanning electron microscopic studies on the development of the chick retina. Cell Tissue Res 1976, 170:145-59.

68. Bhattacharjee J, Sanyal S: Developmental origin and early differentiation of retinal Muller cells in mice. J Anat 1975, 120:367-72.

69. Malatesta P, Hartfuss E, Gotz M: Isolation of radial glial cells by fluorescent-activated cell sorting reveals a neuronal lineage. Development 2000, 127:5253-63.

70. Pinto L, Gotz M: Radial glial cell heterogeneity-the source of diverse progeny in the CNS. Prog Neurobiol 2007, 83:2-23.

71. Herman JP, Victor JC, Sanes JR: Developmentally regulated and spatially restricted antigens of radial glial cells. Dev Dyn 1993, 197:307-18.

72. Willbold E, Rothermel A, Tomlinson S, Layer PG: Muller glia cells reorganize reaggregating chicken retinal cells into correctly laminated in vitro retinae. Glia 2000, 29:45-57.

73. Willbold E, Reinicke M, Lance-Jones C, Lagenaur C, Lemmon V, Layer PG: Muller glia stabilizes cell columns during retinal development: lateral cell migration but not neuropil growth is inhibited in mixed chick-quail retinospheroids. Eur J Neurosci 1995, 7:2277-84.

74. Anezary L, Medina Jl, Sanchez-Nogueiro J, Lopez-Gallardo M, Prada C: Shape diversity among chick retina Muller cells and their postnatal differentiation. J Comp Neurol 2001, 438:32-49.

75. Won MH, Kang TC, Cho SS: Glial cells in the bird retina: immunochemical detection. Microsc Res Tech 2000, 50:151-60.

76. Cuadros MA, Navascues J: The origin and differentiation of microglial cells during development. Prog Neurobiol 1998, 56:173-89.

77. Santos AM, Calvente R, Tassi M, Carrasco MC, Martin-Oliva D, Marin-Teva JL, Navascues J, Cuadros MA: Embryonic and postnatal development of microglial cells in the mouse retina. J Comp Neurol 2008, 506:224-39.

78. Niwa H, Yamamura K, Miyazaki J: Efficient selection for high-expression transfectants with a novel eukaryotic vector. Gene 1991, 108:193-9.

79. Chen YX, Krull CE, Reneker LW: Targeted gene expression in the chicken eye by in ovo electroporation. Mol Vis 2004, 10:874-83.

80. Hamburger $V$, Hamilton HL: A series of normal stages in the development of the chick embryo. 1951 [see comment]. Developmental Dynamics 1992, 195:231-72.

81. Hicks D, Molday RS: Differential immunogold-dextran labeling of bovine and frog rod and cone cells using monoclonal antibodies against bovine rhodopsin. Exp Eye Res 1986, 42:55-71.

82. Cheng L, Samad OA, Xu Y, Mizuguchi R, Luo P, Shirasawa S, Goulding M, Ma Q: Lbx1 and Tlx3 are opposing switches in determining GABAergic versus glutamatergic transmitter phenotypes. Nat Neurosci 2005, 8:1510-5.

83. Muroyama Y, Fujihara M, Ikeya M, Kondoh H, Takada S: Wnt signaling plays an essential role in neuronal specification of the dorsal spinal cord. Genes Dev 2002, 16:548-53.

84. Wiechmann AF: Recoverin in cultured human retinoblastoma cells: enhanced expression during morphological differentiation. J Neurochem 1996, 67:105-10.

\section{doi:10.1186/1471-213X-10-8}

Cite this article as: Doh et al:: Analysis of retinal cell development in chick embryo by immunohistochemistry and in ovo electroporation techniques. BMC Developmental Biology 2010 10:8. 